\title{
Histones Differentially Modulate the Anticoagulant and Profibrinolytic Activities of Heparin, Heparin Derivatives, and Dabigatran
}

\author{
Concetta Tiziana Ammollo, Nicola Semeraro, Maria Rosaria Carratù, Mario Colucci, \\ and Fabrizio Semeraro
}

Department of Biomedical Sciences and Human Oncology, Section of General and Experimental Pathology (C.T.A., N.S., M.C., F.S.), and Section of Pharmacology (M.R.C), University of Bari "Aldo Moro," Bari, Italy

Received October 5, 2015; accepted November 16, 2015

\begin{abstract}
The antithrombin activity of unfractionated heparin (UFH) is offset by extracellular histones, which, along with DNA, represent a novel mediator of thrombosis and a structural component of thrombi. Here, we systematically evaluated the effect of histones, DNA, and histone-DNA complexes on the anticoagulant and profibrinolytic activities of UFH, its derivatives enoxaparin and fondaparinux, and the direct thrombin inhibitor dabigatran. Thrombin generation was assessed by calibrated automated thrombinography, inhibition of factor Xa and thrombin by synthetic substrates, tissue plasminogen activator-mediated clot lysis by turbidimetry, and thrombinactivatable fibrinolysis inhibitor (TAFI) activation by a functional assay. Histones alone delayed coagulation and slightly stimulated fibrinolysis. The anticoagulant activity of UFH and enoxaparin was markedly inhibited by histones, whereas that of fondaparinux was enhanced. Histones neutralized both the
\end{abstract}

anti-Xa and anti-lla activities of UFH and preferentially blocked the anti-Ila activity of enoxaparin. The anti-Xa activity of fondaparinux was not influenced by histones when analyzed by chromogenic substrates, but was potentiated in a plasma prothrombinase assay. Histones inhibited the profibrinolytic activity of UFH and enoxaparin and enhanced that of fondaparinux by acting on the modulation of TAFI activation by anticoagulants. Histone $\mathrm{H} 1$ was mainly responsible for these effects. Histone-DNA complexes, as well as intact neutrophil extracellular traps, impaired the activities of UFH, enoxaparin, and fondaparinux. Dabigatran was not noticeably affected by histones and/or DNA, whatever the assay performed. In conclusion, histones and DNA present in the forming clot may variably influence the antithrombotic activities of anticoagulants, suggesting a potential therapeutic advantage of dabigatran and fondaparinux over heparins.

\section{Introduction}

Extracellular nuclear chromatin has been identified as a novel mediator of thrombosis. Its main constituents, DNA and histones, can be released from dead cells or activated inflammatory cells, especially in the form of neutrophil extracellular traps (NETs), a complex network of chromatin and cytoplasm granule proteins (Chen et al., 2014). Upon release, they markedly affect the hemostatic system. DNA favors the activation of factor XII and factor XI (Kannemeier et al., 2007). Histones activate platelets (Fuchs et al., 2010, 2011) and erythrocytes, inducing the expression of a procoagulant phenotype (Semeraro et al., 2011, 2014), and increase thrombin generation by impairing protein $\mathrm{C}$ activation (Ammollo et al., 2011). Several in vivo data support the role of DNA and histones in thrombogenesis. In a model of inferior vena cava flow restriction, infusion of DNase I protects mice from deep

This study was supported in part by a grant from the University of Bari "Aldo Moro" to Mario Colucci.

dx.doi.org/10.1124/jpet.115.229823. vein thrombosis (Brill et al., 2012). Injection of high doses of histones in mice induces a septic-like condition, and neutralization of histone $\mathrm{H} 4$ is protective in several sepsis models (Xu et al., 2009). Sublethal doses of histones cause thrombocytopenia (Fuchs et al., 2011), stimulate thrombin generation (Abrams et al., 2013), and foster deep vein thrombosis development in mice (Brill et al., 2012). The importance of these new mediators is further confirmed by the abundance of extracellular histones and DNA in animal (Fuchs et al., 2010) and human (Savchenko et al., 2014) venous thrombi. Moreover, they have also been detected in human arterial thrombi (Longstaff et al., 2013), providing new clues for the pathogenesis of arterial thrombosis.

Anticoagulant drugs are the cornerstone for the prevention and therapy of venous thrombosis and pulmonary embolism and are used in the management of arterial thrombosis together with platelet inhibitors. By inhibiting thrombin activity/generation, they hamper thrombus formation and accretion (Chiu et al., 1977; Van Ryn-McKenna et al., 1989) and favor clot dissolution (Semeraro et al., 2007; Varin et al., 2007; Ammollo et al., 2010), mainly by impairing

ABBREVIATIONS: CAT, calibrated automated thrombinography; ETP, endogenous thrombin potential; f.d., final dilution; FXa, factor Xa; NET, neutrophil extracellular trap; LMWH, low-molecular-weight heparin; PMN, polymorphonuclear leukocytes; TAFI, thrombin-activatable fibrinolysis inhibitor; TAFla, activated TAFI; t-PA, tissue plasminogen activator; UFH, unfractionated heparin; ZGGR-AMC, Z-Gly-Gly-Arg-7-amino-4-methylcoumarin. 
thrombin-activatable fibrinolysis inhibitor (TAFI) activation (Semeraro et al., 2007; Ammollo et al., 2010). Heparins are a family of glycosaminoglycans that accelerate antithrombinmediated inhibition of activated clotting factors [mainly thrombin and factor $\mathrm{Xa}(\mathrm{FXa})]$. The family progenitor is unfractionated heparin (UFH), whereas low-molecular-weight heparins (LMWHs) are derived from the chemical or enzymatic depolymerization of UFH; pentasaccharide represents the smallest heparin sequence with inhibitory activity. These compounds mainly differ in selectivity, UFH exerting equal activity against FXa and thrombin, LMWHs showing a preference for FXa, and pentasaccharide being specific for FXa.

It is renowned that cationic proteins can interact with UFH by electrostatic forces and neutralize its activity, as in the case of protamine sulfate, which is indeed used as heparin antidote. Also histones, as basic proteins, can bind with high affinity to UFH and offset its antithrombin activity (Pal et al., 1983). However, evidence that histones affect the antithrombotic potential of anticoagulants other than UFH is limited to a report showing that nuclear material from cancer cells containing histones interferes with the activity of LMWHs (Morita et al., 2001). Moreover, it is not known whether and how histones can influence the profibrinolytic activity of anticoagulant drugs.

Given the emerging importance of histones and DNA as thrombogenic factors and structural components of thrombi, we systematically evaluated their effect on both anticoagulant and profibrinolytic activities of UFH, the LMWH enoxaparin, the synthetic pentasaccharide fondaparinux, and the novel small direct oral thrombin inhibitor dabigatran.

\section{Materials and Methods}

Materials. The following reagents were purchased: single-chain recombinant tissue plasminogen activator (t-PA) (Boehringer Ingelheim GmbH, Florence, Italy); human thromboplastin (Recombiplastin) and chromogenic FXa substrate S-2772 (Instrumentation Laboratory, Milan, Italy); type II-A calf thymus histones, recombinant human histones (H1, H2A, H2B, H3.3, and H4), calf thymus DNA, bovine fibrinogen, potato tuber carboxypeptidase inhibitor, bovine pancreas DNase I, De- $N$-sulfated heparin sodium salt, and calcium ionophore A23187 (Sigma-Aldrich, Milan, Italy); human FXa and $\alpha$-thrombin (Haemathologic Technologies, Essex Junction, VT); reptilase from Bothrops atrox venom (American Diagnostica, Pfungstadt, Germany); fluorogenic thrombin substrate Z-Gly-Gly-Arg-7-amino-4methylcoumarin (ZGGR-AMC) and thrombin calibrator (Diagnostica Stago, Asnieres, France); and DNA-binding dye Sytox Green (Life Technologies, Monza, Italy). Phospholipid vesicles (20\% phosphatidylserine, $60 \%$ phosphatidylcholine, $20 \%$ phosphatidylethanolamine; Avanti Polar Lipids, Alabaster, AL) were prepared by sonication. DNA was fragmented by sonication to $200-400 \mathrm{bp}$ size, as assessed by agarose gel electrophoresis. Histones and DNA were used at $40 \mu \mathrm{g} / \mathrm{ml}$, unless otherwise reported. Where indicated, histones were preincubated with DNA at a 1:1 (w:w) ratio for 10 minutes at room temperature to form complexes. The anticoagulant drugs were studied at the following final concentrations per $\mathrm{ml}$ of plasma, unless otherwise specified: sodium heparin, $0.25 \mathrm{IU} / \mathrm{ml}$ (heparin BMS; Bristol-Myers Squibb, Anagni, Italy); enoxaparin, $1 \mathrm{IU} / \mathrm{ml}$ (Clexane; Sanofi-Aventis, Milan, Italy), which has a mean anti-Xa/ anti-IIa activity ratio of 4.3 (Alban, 2005); fondaparinux, $2 \mu \mathrm{g} / \mathrm{ml}$ (Arixtra; GlaxoSmithKline, Verona, Italy); dabigatran, $1 \mu \mathrm{M}$ (provided by Boehringer Ingelheim GmbH, Biberach, Germany).

Plasma Preparation. Peripheral venous blood was collected into $3.8 \%$ trisodium citrate from healthy volunteers who gave informed consent. Platelet-poor plasma was prepared by double centrifugation
(1000 and $12,000 \times g, 10$ minutes each) and stored at $-80^{\circ} \mathrm{C}$. Where indicated, plasma was defibrinated by reptilase treatment [1:50 final dilution (f.d.)] for 1 hour at $37^{\circ} \mathrm{C}$. Plasma from at least three donors was pooled for each experiment.

Isolation of Polymorphonuclear Leukocytes and NET Production. Blood polymorphonuclear leukocytes (PMN) were isolated from healthy volunteers of both sexes by dextran sedimentation followed by density gradient centrifugation on Lympholyte-H (Cedarlane Laboratories, Hornby, ON, Canada) and hypotonic lysis of erythrocytes (Johnston et al., 1975). PMN were seeded in flatbottomed 96-well microplates at the indicated concentrations in $20 \mathrm{mM}$ Hepes and $150 \mathrm{mM} \mathrm{NaCl}$ buffer containing $2.5 \mathrm{mM} \mathrm{CaCl}_{2}$ and $4 \mathrm{mM}$ glucose, and stimulated with ionophore A23187 $(25 \mu \mathrm{M})$ for 2 hours at $37^{\circ} \mathrm{C}$ in a $5 \% \mathrm{CO}_{2}$ atmosphere. NET extrusion was assessed by staining of extracellular DNA with $4 \mu \mathrm{M}$ Sytox Green (not shown). After incubation, the medium was removed and plasma was gently layered onto adherent cells. To degrade NETs, cells were incubated with DNase I $(100 \mathrm{U} / \mathrm{ml})$ and $10 \mathrm{mM} \mathrm{MgSO}$ for 30 minutes at $37^{\circ} \mathrm{C}$ and washed afterward. To block histones in NETs, cell monolayers were treated with De- $N$-sulfated heparin $(200 \mu \mathrm{g} / \mathrm{ml})$ for 1 hour at $37^{\circ} \mathrm{C}$ and then washed.

Assay of Thrombin Generation. Thrombin generation was assessed by calibrated automated thrombinography (CAT) as described (Hemker et al., 2006). In brief, $80 \mu \mathrm{l}$ of plasma was incubated for 5 minutes at $37^{\circ} \mathrm{C}$ with histones in round-bottomed microplate wells. Then anticoagulants were added along with thromboplastin $(6 \mathrm{pM})$ and phospholipid vesicles $(10 \mu \mathrm{g} / \mathrm{ml})$. Analysis was started upon addition of $20 \mu \mathrm{l}$ of a mixture containing $100 \mathrm{mM} \mathrm{CaCl}_{2}$ and $2.5 \mathrm{mM}$ ZGGR-AMC in a final volume of $120 \mu \mathrm{l}$. To study prothrombin activation by FXa, thrombin generation was triggered by $\mathrm{FXa}(0.25 \mu \mathrm{g} / \mathrm{ml})$ in FX-depleted plasma (Instrumentation Laboratory). Thrombin generation with PMN was performed in half final volume to minimize the volume-to-surface ratio. Measurements were taken in a Fluoroskan Ascent fluorometer (Thermo Scientific, Dreieich, Germany), data were analyzed using the Thrombinoscope software (Thrombinoscope BV, Maastricht, The Netherlands), and lag time and endogenous thrombin potential (ETP) were calculated. The anticoagulant activity of drugs was expressed as percent reduction of ETP.

Thrombin and FXa Inhibition. Inhibition of clotting factors by anticoagulants was studied by means of a one-stage assay using specific synthetic substrates. Plasma containing histones and anticoagulants was diluted 5 -fold in Tris- $\mathrm{NaCl}$ buffer and supplemented with the chromogenic substrate S-2772 $(100 \mu \mathrm{M})$ or the fluorogenic substrate ZGGR-AMC $(100 \mu \mathrm{M})$ for FXa or thrombin evaluation, respectively. Upon addition of $\mathrm{FXa}(0.3 \mu \mathrm{g} / \mathrm{ml})$ or thrombin $(2 \mathrm{U} / \mathrm{ml})$, substrate cleavage was followed for 30 minutes at $405 \mathrm{~nm}$ or at $390-\mathrm{nm}$ excitation and 460-nm emission, and the final signal was corrected for the background noise. Residual enzyme activity in the presence of anticoagulants was expressed as the percentage of absorbance/ fluorescence of the correspondent control.

Microplate Clot Lysis Assay. Clot lysis was studied by a turbidimetric assay (Ammollo et al., 2010), modified as follows. Plasma $(80 \mu \mathrm{l})$ was preincubated with histones or buffer in microplate wells for 5 minutes at $37^{\circ} \mathrm{C}$. Afterward, anticoagulants were added, and clotting-fibrinolysis started with thromboplastin (6 pM), phospholipids $(10 \mu \mathrm{g} / \mathrm{ml}), \mathrm{t}-\mathrm{PA}(40 \mathrm{ng} / \mathrm{ml})$, and $\mathrm{CaCl}_{2}(16.6 \mathrm{mM})$ in a final volume of $120 \mu \mathrm{l}$. In some instances, clotting was induced by reptilase (1:24 f.d.) in the absence of calcium. Changes in the optical density at $405 \mathrm{~nm}$ were monitored in a Multiskan FC spectrophotometer (Thermo Scientific) at $37^{\circ} \mathrm{C}$, and clotting times were calculated as the time to half-maximum absorbance increase, whereas lysis times were calculated as the interval between the midpoint of the clear to maximum turbidity transition and the midpoint of the maximum turbidity to clear transition. The profibrinolytic activity of anticoagulants was expressed as the lysis ratio, i.e., the ratio between the lysis time in the absence and in the presence of drugs.

TAFI Activation Assay. TAFI activation was evaluated by a twostage assay as described (Semeraro et al., 2013). In the first stage, 
clotting was induced in defibrinated plasma under the same conditions used for the lysis assay but without t-PA. At intervals, aliquots from the reaction mixtures were transferred into refrigerated tubes containing hirudin (200 U/ml; Abbott GmbH, Ludwigshafen, Germany) to halt TAFI activation and preserve activated TAFI (TAFIa) activity. In the second stage, TAFIa activity was evaluated as the ability to prolong the lysis time of clots formed with purified fibrinogen. Eighty microliters of sample was added to microplate wells along with fibrinogen $(830 \mu \mathrm{g} / \mathrm{ml})$, t-PA (40 $\mathrm{ng} / \mathrm{ml})$, and reptilase (1:50, f.d.) as clotting reagent (final volume $120 \mu \mathrm{l}$ ). The plate was read at $405 \mathrm{~nm}$ at room temperature to reduce TAFIa decay, and the lysis times were calculated as described earlier. Results were expressed as prolongation of lysis time over parallel samples supplemented with the TAFIa inhibitor potato tuber carboxypeptidase inhibitor.

Statistical Analysis. Results shown are the mean \pm S.E.M. Statistical analysis was performed using GraphPad Prism version 4.01 for Windows (GraphPad Software, San Diego, CA). Multiple comparisons were performed by one-way analysis of variance for repeated measures followed by a post-test for linear trend (for dose response), Dunnett's post-hoc test (for comparing each sample to the control), or Newman-Keuls post-hoc test (for comparing all samples to each other). Student's $t$ test for paired data was used where applicable. $P$ values $<0.05$ were considered statistically significant.

\section{Results}

Effect of Histones on Coagulation/Fibrinolysis. We first evaluated the influence of histones on coagulation/ fibrinolysis under our experimental conditions by means of CAT and clot lysis assay, respectively. In the thrombingeneration assay, histones dose dependently prolonged the lag time without significant modifications of the ETP (Fig. 1A). Consistent with these data, clot formation was significantly delayed by histones in the clot lysis assay (Fig. 1B). As for fibrinolysis, histones induced a weak but significant profibrinolytic effect (Fig. 1B), which was independent of coagulation, as was also observed in reptilase-induced clots (not shown).

Effect of Histones on the Anticoagulant Activity of Drugs. Plasma was supplemented with a fixed concentration of each anticoagulant, producing at least $60 \%$ inhibition of ETP, and the CAT assay was performed in the presence of increasing concentrations of histones. As shown in Fig. 2A, the effect of histones varied considerably depending on the drug tested. The anticoagulant activity of UFH and enoxaparin was markedly inhibited by histones, with an $\mathrm{IC}_{50}$ of $7.9 \pm 2.5$ and $31 \pm 3.7 \mu \mathrm{g} / \mathrm{ml}$, respectively. On the contrary, histones did not impair, but rather enhanced, albeit slightly, the anticoagulant activity of fondaparinux. As for dabigatran, no significant modification was observed. Next, we evaluated the effect of $40 \mu \mathrm{g} / \mathrm{ml}$ histones on different concentrations of drugs. Under this condition, UFH displayed no anticoagulant activity up to $0.5 \mathrm{IU} / \mathrm{ml}$, and only partial activity ( $\approx 50 \%$ of control $)$ at $1 \mathrm{IU} / \mathrm{ml}$ (Fig. 2B). Similarly, enoxaparin showed a detectable activity only at concentrations $\geq 0.5 \mathrm{IU} / \mathrm{ml}$. As for fondaparinux, the enhancement of anticoagulant activity by histones was seen at all concentrations. As expected, dabigatran activity was barely influenced by histones.

To directly evaluate the influence of histones on the neutralization of target enzymes by each drug, FXa $(0.3 \mu \mathrm{g} / \mathrm{ml})$ or thrombin $(2 \mathrm{U} / \mathrm{ml})$ was added to diluted plasma containing the anticoagulant and histones, and residual enzymatic activity was determined by chromogenic (FXa) or fluorogenic (thrombin) substrates. The used concentration of drugs reduced the enzymatic activity of either thrombin or FXa
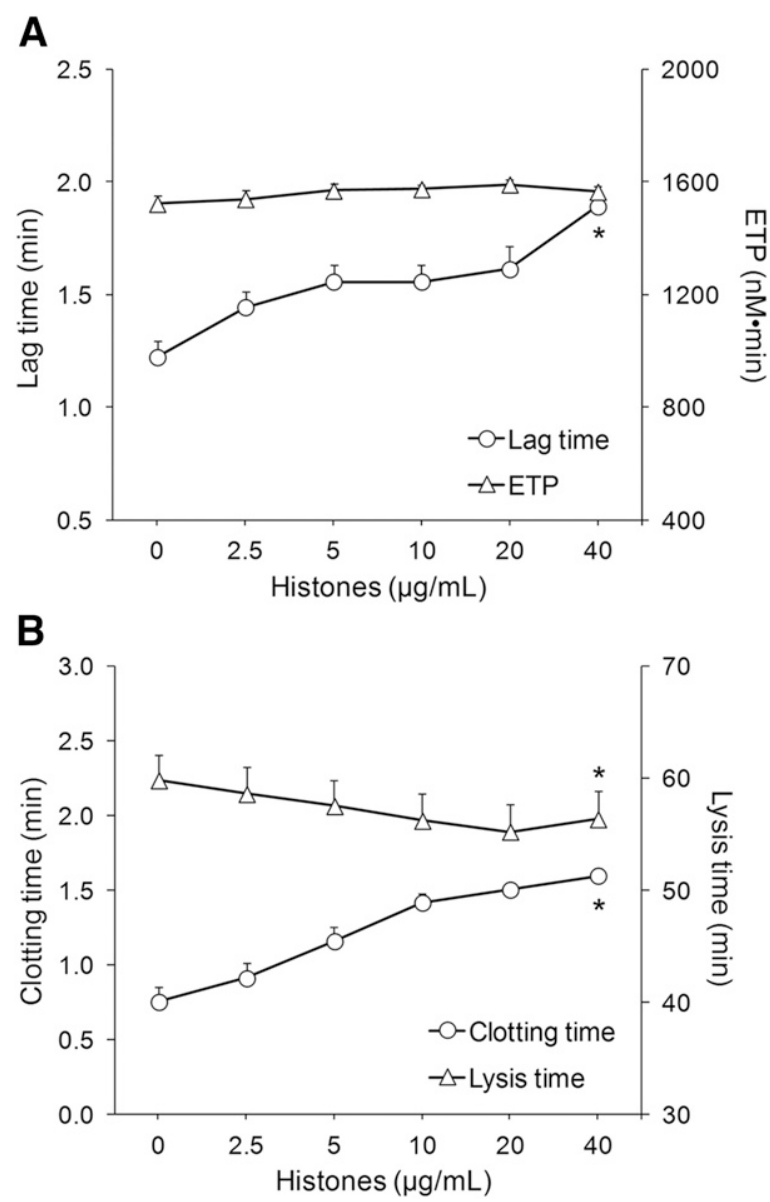

Fig. 1. Effect of calf thymus histones on coagulation and fibrinolysis. Plasma supplemented with increasing concentrations of calf thymus histones $(0-40 \mu \mathrm{g} / \mathrm{ml})$ was clotted with $6 \mathrm{pM}$ thromboplastin and $10 \mu \mathrm{g} / \mathrm{ml}$ phospholipids, and lysed with $40 \mathrm{ng} / \mathrm{ml}$ t-PA. (A) The effect of histones on thrombin generation was evaluated by CAT $(n=6)$. (B) The influence of histones on plasma clotting and fibrinolysis was assessed by turbidimetry $(n=8)$. Results shown are the mean \pm S.E.M. $* P<0.05$ for linear trend by repeated-measures analysis of variance.

by $\geq 90 \%$. The anti-Xa and anti-IIa activities of UFH were nearly completely quenched by histones (Fig. 2, C and D). In the case of enoxaparin, anti-Xa activity was inhibited by only $\approx 11 \%$, whereas anti-IIa activity was inhibited by $\approx 85 \%$. The anti-Xa activity of fondaparinux $(1 \mu \mathrm{g} / \mathrm{ml})$ was not modified by histones, and the anti-IIa activity of dabigatran $(0.5 \mu \mathrm{M})$ was unchanged. As the lack of effect of histones on fondaparinux anti-Xa activity was in contrast with the thrombin-generation data, we investigated their influence on the FXa-mediated conversion of prothrombin to thrombin in FX-depleted plasma by CAT. In this experimental setting, which more closely approaches physiologic conditions, histones delayed thrombin formation and enhanced the anti-Xa activity of fondaparinux (Fig. 2E).

Effect of Histones on the Profibrinolytic Activity of Drugs. In the clot lysis assay, the used concentrations of anticoagulants displayed a strong profibrinolytic activity, with a shortening of the lysis time greater than $40 \%$. The profibrinolytic activity of UFH and enoxaparin was inhibited by histones in a concentration-dependent fashion (Fig. 3A). In particular, the activity of UFH was markedly reduced by as little as $2.5 \mu \mathrm{g} / \mathrm{ml}$ histones, and completely quenched by $10 \mu \mathrm{g} / \mathrm{ml}$, 
A

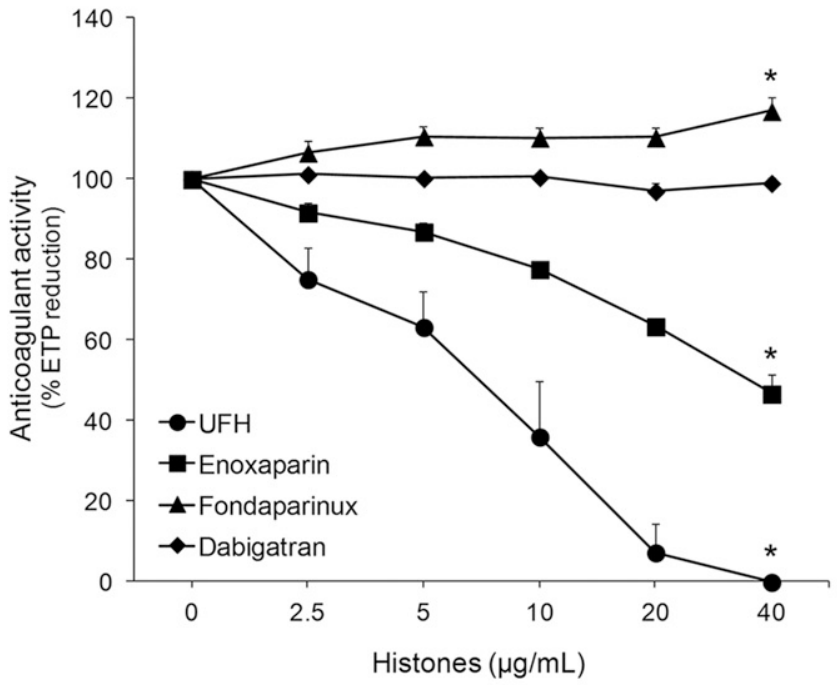

C

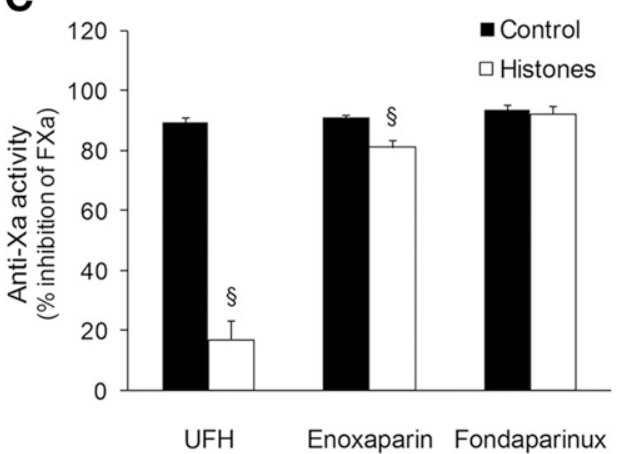

D

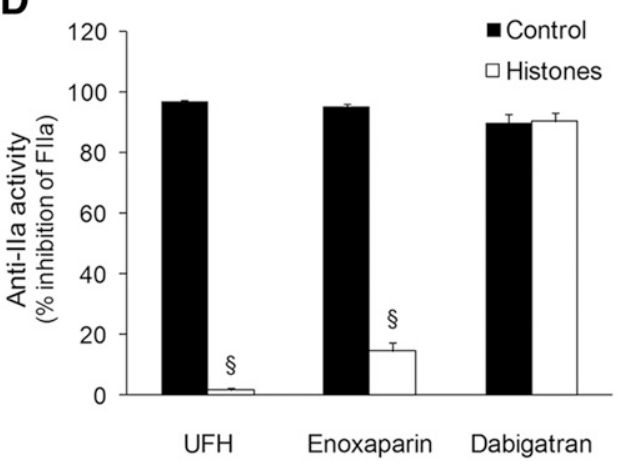

B
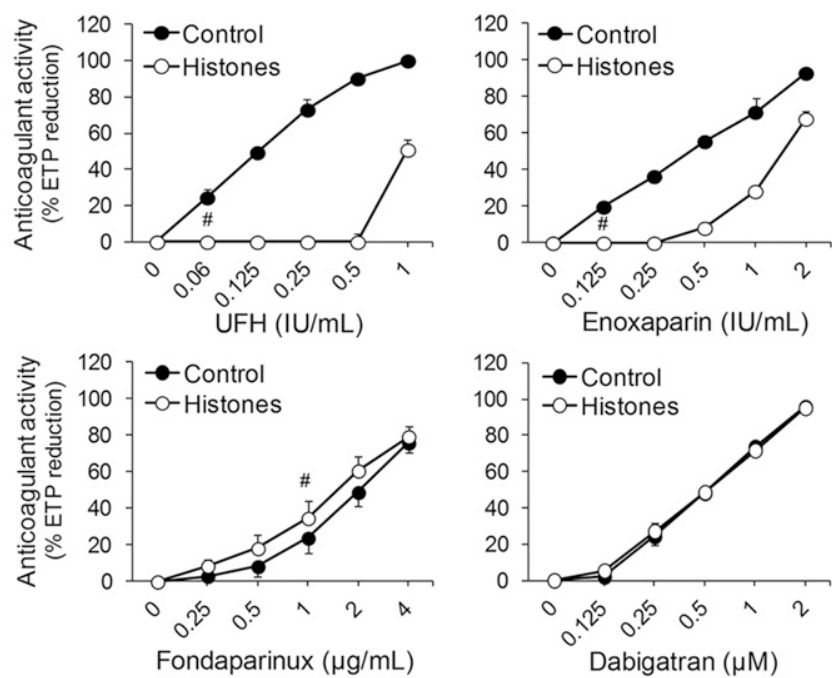

E

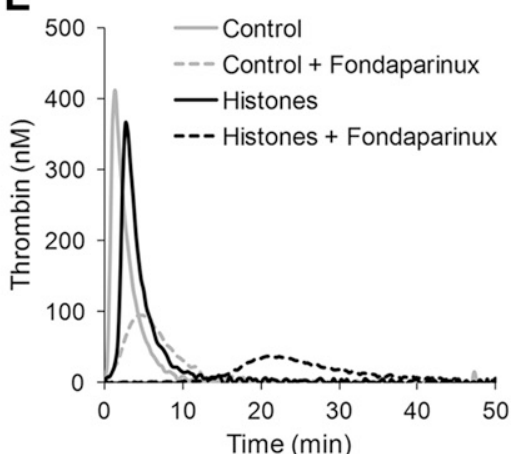

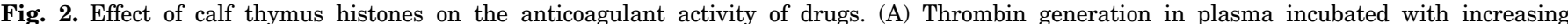

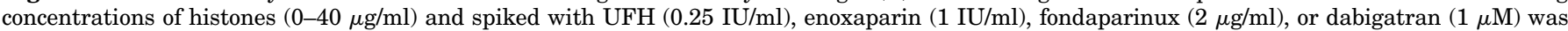

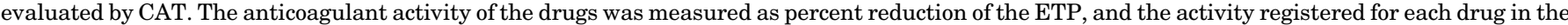

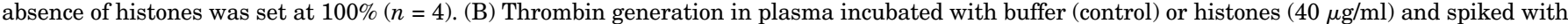

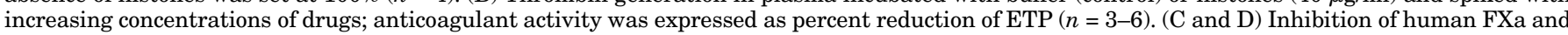

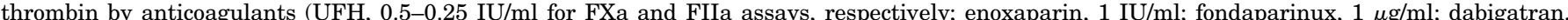

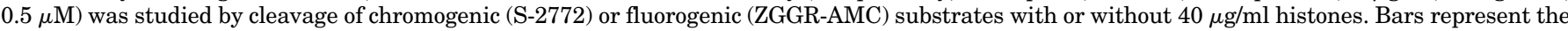

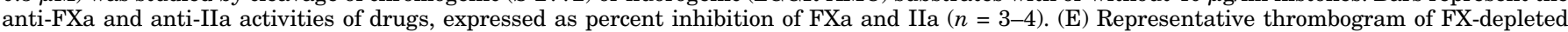

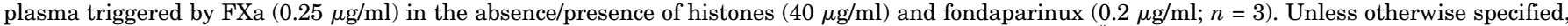

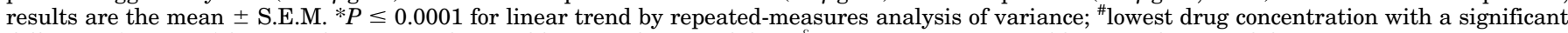
difference $(P<0.05)$ between histones and control by $t$ test for paired data; ${ }^{\S} P<0.01$ versus control by $t$ test for paired data.

whereas complete inhibition of enoxaparin was observed at $40 \mu \mathrm{g} / \mathrm{ml}$ histones. Calculated IC $_{50}$ values of histones were $2.1 \pm$ 0.3 and $8.2 \pm 1.7 \mu \mathrm{g} / \mathrm{ml}$ for UFH and enoxaparin, respectively. The profibrinolytic activity of fondaparinux was enhanced by the highest concentrations of histones, and that of dabigatran was only slightly increased.

When $40 \mu \mathrm{g} / \mathrm{ml}$ histones were challenged with increasing concentrations of anticoagulants, the clot lysis results (Fig. 3B) recapitulated fairly well those obtained in the thrombingeneration assay. In fact, in the presence of histones, UFH failed to stimulate fibrinolysis at concentrations up to $0.5 \mathrm{IU} / \mathrm{ml}$, and exhibited only a modest activity at $1 \mathrm{IU} / \mathrm{ml}$. Enoxaparin displayed a similar behavior, with some profibrinolytic activity appearing at concentrations $>0.5 \mathrm{IU} / \mathrm{ml}$. As to fondaparinux, the increase in profibrinolytic activity caused by histones was observed at drug concentrations $\geq 1 \mu \mathrm{g} / \mathrm{ml}$. The profibrinolytic effect of dabigatran was subtly enhanced by histones.
One of the main mechanisms behind the profibrinolytic activity of anticoagulants is the inhibition of thrombinmediated TAFI activation. Therefore, we evaluated the influence of histones on drugs' ability to reduce TAFI activation. In accordance with clot lysis data, the inhibitory activities of UFH and enoxaparin were greatly reduced, whereas the ability of fondaparinux to inhibit TAFI activation was enhanced, and that of dabigatran was almost unaffected (Fig. 3C).

Effect of Individual Histones on Anticoagulants. To determine which histone subtype was mainly responsible for the observed effects of the mixture, recombinant individual histones $(10 \mu \mathrm{g} / \mathrm{ml})$ were tested in CAT and clot lysis assays. Among subtypes, histone $\mathrm{H} 1$ recapitulated most of the effects of the mixture: it significantly delayed thrombin generation, prolonged clotting time, and stimulated fibrinolysis, although weakly; in addition, it slightly reduced ETP (not shown). In the presence of anticoagulants (Fig. 4), H1 showed the strongest neutralizing activity toward UFH and enoxaparin and the 

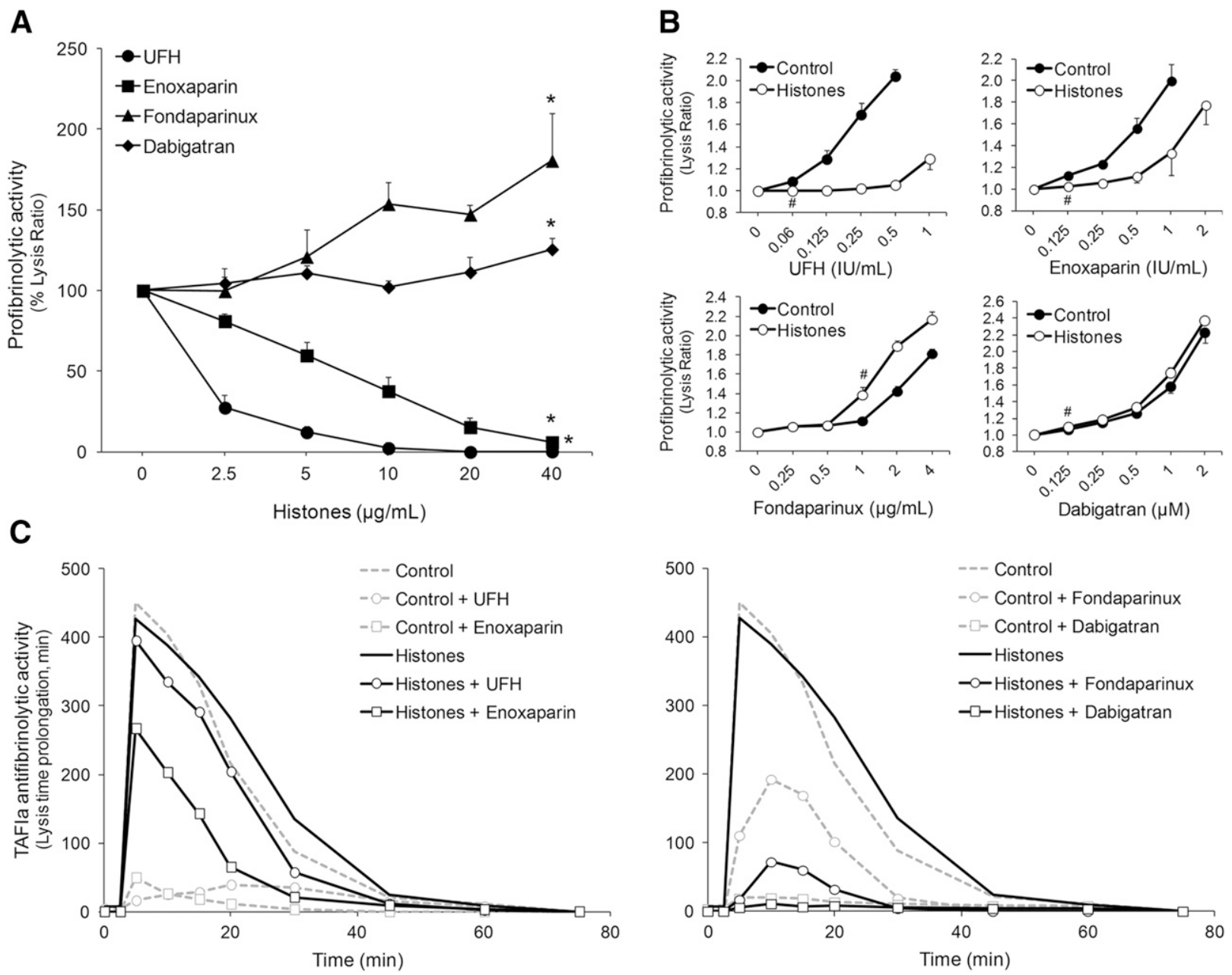

highest stimulating activity toward fondaparinux, followed by $\mathrm{H} 2 \mathrm{~A}$ and $\mathrm{H} 2 \mathrm{~B}$. H3 and $\mathrm{H} 4$ caused only a weaker inhibition of UFH. None of the histones influenced dabigatran activity.

Effect of DNA and Histone-DNA Complexes on Anticoagulants. As histones can be released in complex with DNA, we investigated how the presence of DNA modifies the effects of histones. To that purpose, DNA was preincubated with histones (40 $\mu \mathrm{g} / \mathrm{ml}$ each) to form complexes. Associated with DNA, histones lost their effects on coagulation and fibrinolysis (not shown). When tested in the presence of anticoagulants in the CAT assay (Fig. 5), DNA partially attenuated the inhibitory effect of histones on both UFH and enoxaparin. Interestingly, DNA blunted the stimulating effect of histones on fondaparinux when thrombin generation was triggered by tissue factor (Fig. 5C) or FXa (not shown). In the clot lysis test (Fig. 5), DNA did not influence the activity of histones on UFH, but partially attenuated the inhibitory effect on enoxaparin. On the contrary, DNA reversed the effect of histones on fondaparinux, producing a visible reduction in its profibrinolytic activity. A minor reduction in dabigatran profibrinolytic activity was observed in the presence of the complex. The only effect of DNA alone was a reduction in the profibrinolytic activity of fondaparinux.

Effect of NETs on Anticoagulants. To examine the effect of a physiologic source of histone-DNA, PMN were stimulated with calcium ionophore to generate extracellular traps, overlaid with plasma, and then assayed with the various anticoagulants in the CAT assay. Based on the findings of Urban et al. (2009), we calculated that the concentration of NET-associated histones and DNA released in the culture medium by $10^{6}$ neutrophils is on the order of several tens of micrograms per milliliter, which is comparable to the concentrations of purified molecules used throughout the study. In keeping with the results obtained with histoneDNA complexes, NET-expressing PMN interfered with the anticoagulant activity of UFH, enoxaparin, and fondaparinux, 
A

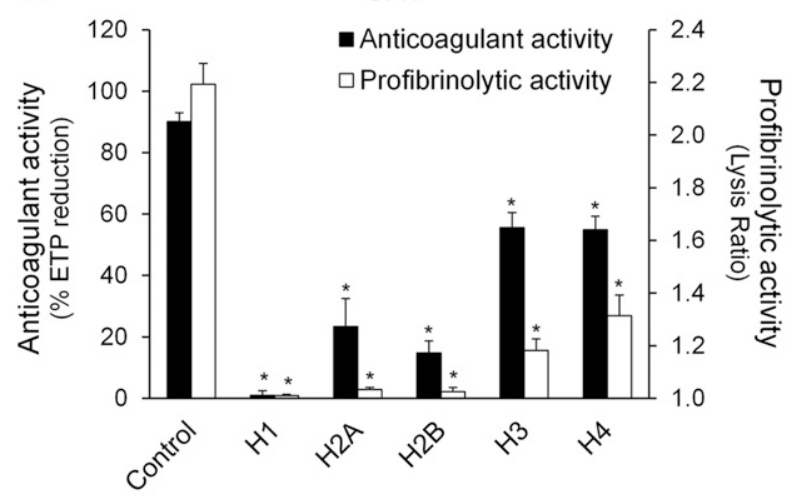

C

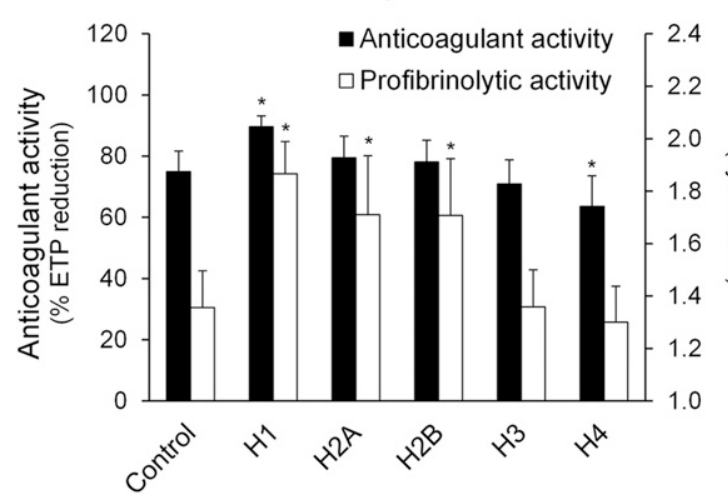

B

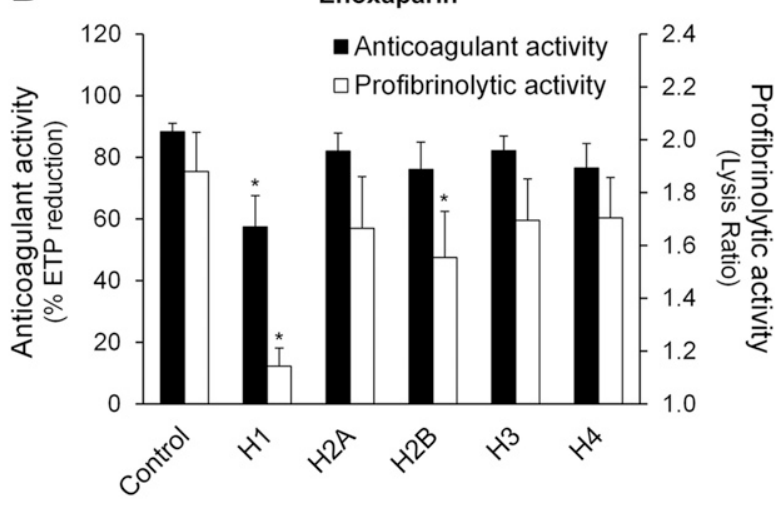

D

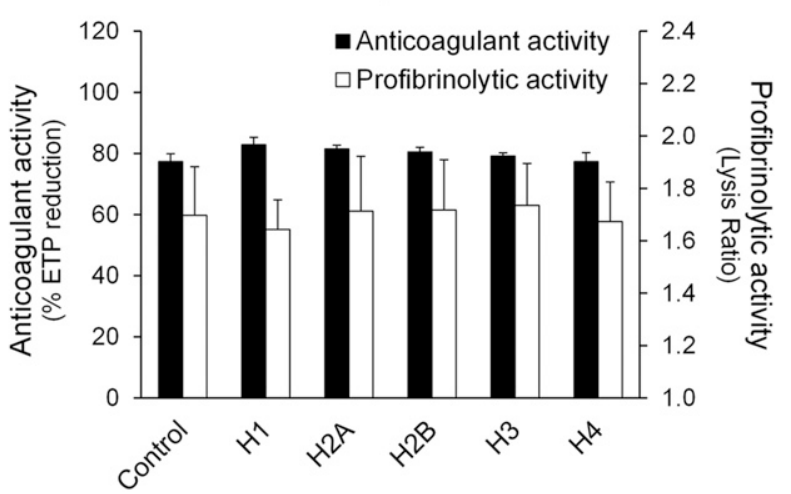

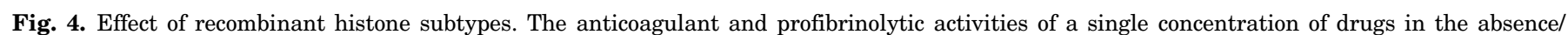

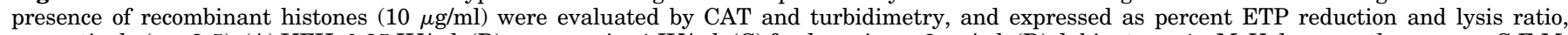

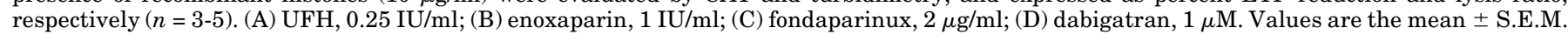
$* P<0.05$ versus control by Dunnett's multiple comparison test.

whereas they did not influence dabigatran (Fig. 6A). In dosedependence experiments, a significant inhibition of UFH activity was achieved with as low as $6 \times 10^{4}$ stimulated cells per well (Fig. 6B). To ensure that this effect was due to NETs, cells were treated with DNase I to remove NET components prior to UFH challenge. DNase treatment reverted the inhibition at low-medium cell densities, but not at high cell numbers (Fig. 6B), a condition in which DNase was also unable to decrease the fluorescent signal of Sytox Green (not shown), suggesting that high cell densities were unfavorable for DNA degradation. On the contrary, targeting histones in NETs with De- $N$-sulfated heparin, a heparin almost devoid of anticoagulant properties (Ammollo et al., 2011), restored most of the anticoagulant activity of UFH even at the highest cell density (Fig. 6C).

\section{Discussion}

This study shows that the incorporation of histones and DNA into clots variably influences the anticoagulant and profibrinolytic activities of heparin and heparin-derived anticoagulants, but has no effect on dabigatran, a representative nonheparin anticoagulant.

It has long been known that histones neutralize heparin, but the biologic implications thereof remained elusive, since histones were believed to be exclusively intranuclear proteins (Pal et al., 1983). The considerable progress made in unveiling the role of extracellular histones in thrombosis brought us to examine the relationship between histones and anticoagulants through global assays, which carefully evaluate coagulation and fibrinolysis under more physiologic conditions. Indeed, we exclusively used plasma systems because histones can interact with plasma proteins (Pemberton et al., 2010) and are susceptible to degradation by plasma proteases (Yamamichi et al., 2011). Moreover, histones were used at concentrations approaching those found in systemic prothrombotic conditions $(\approx 15 \mu \mathrm{g} / \mathrm{ml}$ histone $\mathrm{H} 3$ in septic baboons and $10-230 \mu \mathrm{g} / \mathrm{ml}$ total histones in trauma patients) (Xu et al., 2009; Abrams et al., 2013) or localized thrombotic diseases, in which the high histone content attainable inside the thrombus is reflected by elevated circulating markers of histone release (Brill et al., 2012; Fuchs et al., 2012; Borissoff et al., 2013; van Montfoort et al., 2013). Using CAT to measure the anticoagulant activity of therapeutic drug concentrations, we confirmed that histones neutralized UFH and found that they strongly inhibited enoxaparin. These effects directly impacted on the drugs' capacity to stimulate fibrinolysis. The profibrinolytic potential of anticoagulants stems largely from their ability to inhibit thrombin generation/activity and the thrombin-mediated antifibrinolytic mechanisms (Lisman et al., 2003; Varin et al., 2007; Ammollo et al., 2009), among which TAFI activation is pivotal. However, the relationship between thrombin generation and fibrinolysis rate is not always straightforward. For instance, the prothrombin 
A

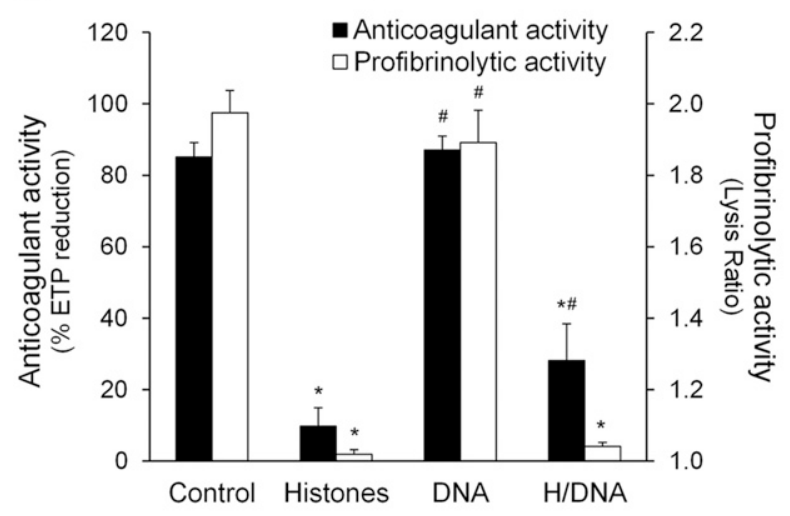

C

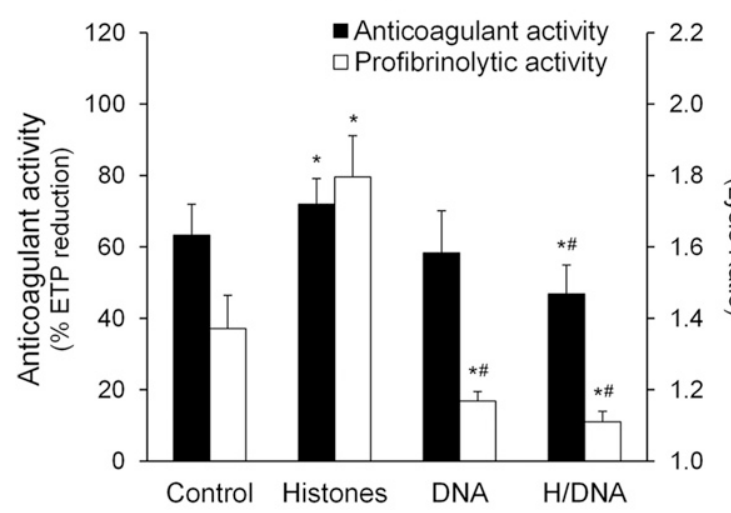

B

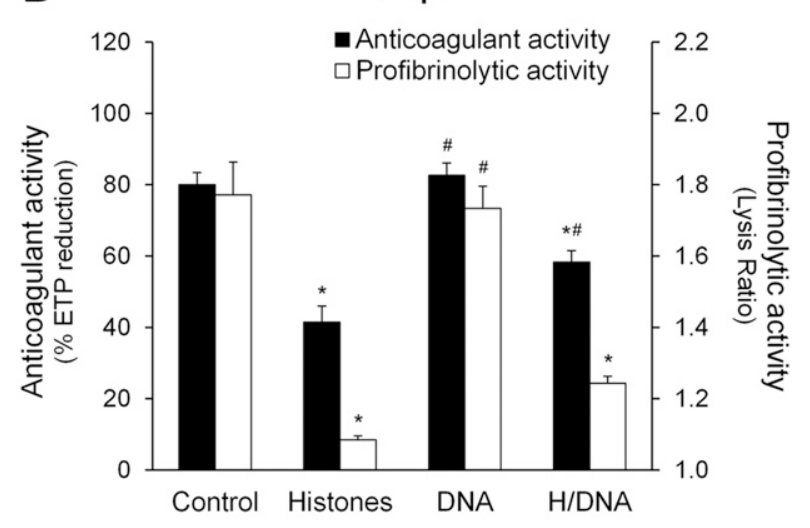

D

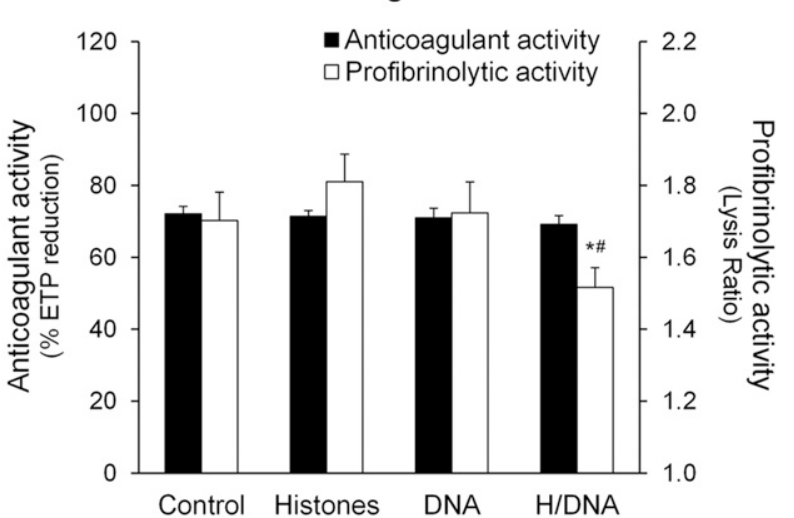

Fig. 5. Effect of calf thymus histones, DNA, and histone-DNA complexes. The anticoagulant and profibrinolytic activities of single drug concentrations in the absence/presence of histones, DNA, or histone-DNA complexes (H/DNA) $(40 \mu \mathrm{g} / \mathrm{ml})$ were evaluated by CAT and turbidimetry and expressed as percent ETP reduction and lysis ratio, respectively $(n=5-6)$. (A) UFH, $0.25 \mathrm{IU} / \mathrm{ml}$; (B) enoxaparin, $1 \mathrm{IU} / \mathrm{ml}$; (C) fondaparinux, $2 \mu \mathrm{g} / \mathrm{ml}$; (D) dabigatran, $1 \mu \mathrm{M}$. Values are the mean \pm S.E.M. ${ }^{*} P<0.05$ versus control, and ${ }^{\#} P<0.05$ versus histones by Newman-Keuls multiple comparison test.

mutation G20210A was reported to reduce the anticoagulant activity of activated protein $\mathrm{C}$ without interfering with its profibrinolytic function (Binetti et al., 2006). Moreover, some thrombin inhibitors (e.g., hirudin) are unable to stimulate fibrinolysis despite their marked anticoagulant activity (Lisman et al., 2003). In the presence of histones, UFH failed to reduce TAFI activation, and enoxaparin was markedly less active; hence, the profibrinolytic activity of UFH was lost and that of enoxaparin greatly impaired, indicating that histones reduced the overall antithrombotic activity of heparins. Based on the $\mathrm{IC}_{50}$ calculation, histones proved to be even more effective in inhibiting the profibrinolytic activity of UFH and enoxaparin than in quenching their anticoagulant activity. In agreement with previous works attributing the heparinneutralizing property mainly to the lysine-rich histone fraction (Pal et al., 1983), we identified histone $\mathrm{H} 1$ as holding the strongest antiheparin activity. Because UFH neutralization by histones is due to charge-to-charge interactions (Pal et al., 1983), the lower size and sulfate charge density of enoxaparin can explain its reduced sensitivity to histones, as suggested by previous studies (Morita et al., 2001) and by the similar behavior of other cationic proteins (Lane et al., 1986; Crowther et al., 2002). Using specific enzymatic assays, we found that the anti-Xa and anti-IIa activities of enoxaparin were differentially inhibited by histones ( 11 and $85 \%$, respectively), which, conversely, blocked both anti-Xa and anti-IIa activities of UFH, further suggesting that histones are weak antagonists of short heparins endowed with more selective anti-Xa activity. In this regard, it is indicative that fondaparinux, the smallest heparin with exclusive anti-Xa activity, was not only insensitive to histone inhibition, but gained even more anticoagulant/profibrinolytic efficacy in the presence of histones. This unexpected effect does not seem to result from a direct influence of histones on the anti-Xa activity of fondaparinux (see Fig. 2C) but rather an indirect mechanism. Indeed, histones delayed clot formation and thrombin generation (see Fig. 1, A and B), showing a nonspecific anticoagulant effect possibly due to a transient binding to phospholipids (Fürnrohr et al., 2007) and/or vitamin K-dependent clotting factors (Pemberton et al., 2010; Ammollo et al., 2011). Based on the results in the prothrombinase assay (see Fig. 2E), it can be hypothesized that histones interfere with the assembly of the prothrombinase complex and allow more FXa to remain in solution, where it is more accessible to inhibition by fondaparinux-antithrombin (Brufatto et al., 2003). This possibility fits quite well with the observation that the anticoagulant effect of histones and the enhancement of fondaparinux activity were both ascribable to the same histone subtype (H1) and reversed by DNA (see below). Also, the enhancement of the profibrinolytic properties of fondaparinux was probably related to the improvement of its anticoagulant activity, as thrombin-mediated mechanisms (reduction of TAFI 
A

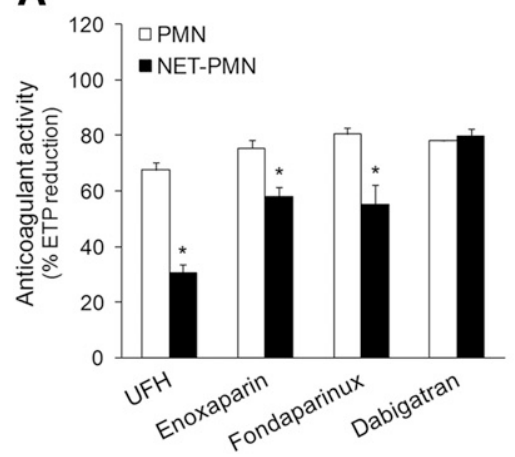

B

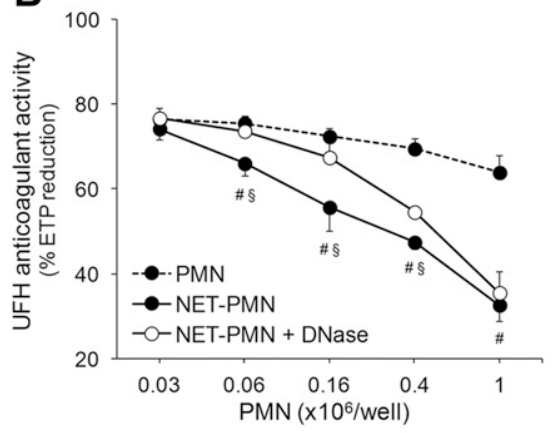

C

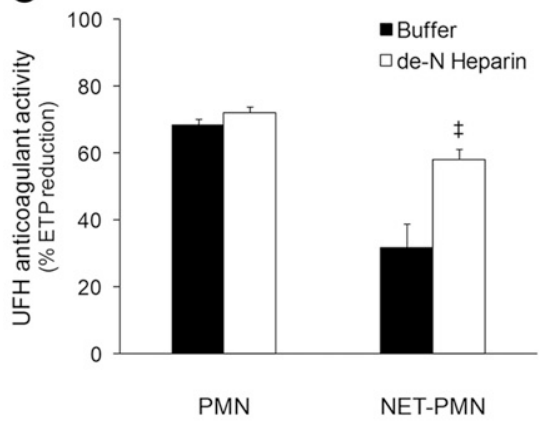

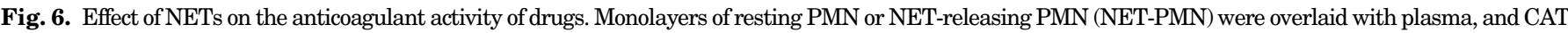

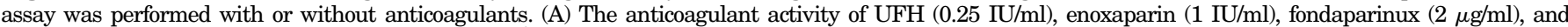

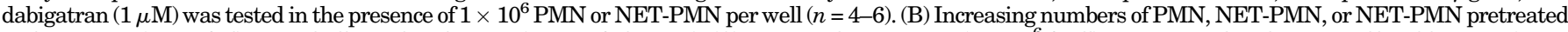

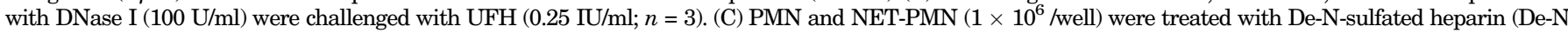

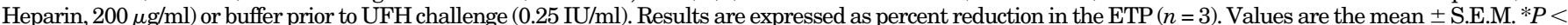

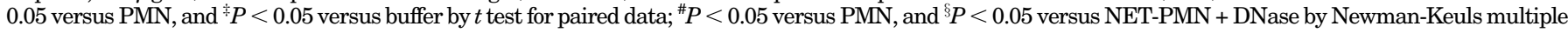
comparison test.

activation; Fig. 3C) were involved. Anyway, the intrinsic profibrinolytic effect of histones could have further contributed to the observed effect. This probably also applies to dabigatran, whose profibrinolytic activity was slightly enhanced by histones even though the anticoagulant potential was unaffected, probably because of its different mechanism of action.

DNA is the natural ligand of histones. Therefore, it was important to assess whether DNA modulates their effects. When complexed with DNA to resemble nucleosomes, histones maintained the inhibitory activity toward UFH and enoxaparin, although it was slightly less pronounced, probably because DNA was displaced by heparins (Longstaff et al., 2013). On the contrary, in the case of fondaparinux, histone-DNA complexes behaved differently from histones alone as they inhibited the anticoagulant and, even more, the profibrinolytic activity of the drug.

In disease, activated neutrophils represent a natural source of nuclear material, released as NETs. The observation that neutrophil-derived NETs recapitulated the effects of histoneDNA on the drugs' anticoagulant activity further strengthens the relevance of our findings. In this respect, it is important to point out that the amount of histones and DNA in our NET preparations (Urban et al., 2009) falls in the concentration range of the purified molecules used in our study.

An additional layer of complication is introduced by the fact that DNA alone inhibited the profibrinolytic activity of fondaparinux without interfering with its anticoagulant function, further suggesting that inhibition of coagulation and stimulation of fibrinolysis (or vice versa) do not always go hand in hand. All the effects of histones, DNA, and histone-DNA on anticoagulants might occur in vivo, because histones and DNA, both circulating and resident in the thrombus scaffold, can exist either in complex or naked (Fuchs et al., 2010; Abrams et al., 2013; Longstaff et al., 2013), most probably as a result of a selective degradation by proteases and DNases.

Our findings may have pathophysiological and clinical implications. The binding of histones to heparan sulfate in the capillaries (Freeman et al., 2013) may reduce the antithrombotic potential of endothelial cells and may represent an additional prothrombotic mechanism of histones, particularly $\mathrm{H} 1$, which is usually considered the least dangerous subtype (Xu et al., 2009;
Fuchs et al., 2010; Ammollo et al., 2011; Semeraro et al., 2011, 2014). From a clinical standpoint, histones add to other heparinbinding proteins as inducers of heparin resistance, a phenomenon occurring in a considerable proportion of patients with venous thromboembolism and acute coronary syndromes (Hirsh et al., 2001). In this regard, the reported interindividual variability in NET production (Fuchs et al., 2007) might represent a contributing factor. The drugs less affected by histones and DNA might have a therapeutic advantage in the management of thrombosis. Some clinical studies have suggested the superiority of treatment with dabigatran or fondaparinux over LMWHs and, in turn, of LMWHs over UFH in terms of better antithrombotic efficacy or reduced bleeding complications in clinical settings, such as major orthopedic surgery, cancer, and acute coronary syndromes (Siragusa et al., 1996; Agnelli, 2004; Yusuf et al., 2006; Eriksson et al., 2011; Silvain et al., 2012), where release of nuclear material occurs (Borissoff et al., 2013; Demers and Wagner, 2014; Dahl et al., 2015).

In interpreting our data, the possible beneficial effects resulting from the inhibition of histones by heparins must also be considered. Indeed, UFH, heparin-derived, and other negatively charged, nonanticoagulant molecules are known to block histone-mediated deleterious effects in vitro and in vivo (Ammollo et al., 2011; Fuchs et al., 2011; Semeraro et al., 2011, 2014; Wildhagen et al., 2014). Allegedly, the neutralization of histones by heparins may be expected to result in a net positive effect in disorders where histone release is a major mechanism of harm, such as severe infection and inflammation (Levi, 2014). In the clinic, heparin is commonly administered to treat or prevent thrombosis, which is triggered by multiple mechanisms, such as the increase in tissue factor expression, the decrease of natural anticoagulants, the impairment of fibrinolysis, and, as pointed out earlier, the release of histones. Thus, it is plausible that the advantage deriving from the neutralization of histones might be overwhelmed by the loss of the effects of heparins on coagulation and fibrinolysis.

In conclusion, histones and DNA present in the ensuing fibrin clot may modulate the profibrinolytic and anticoagulant activities of antithrombotic drugs, thus possibly influencing the thrombus fate toward accretion or stabilization/resolution, 
depending on the drug used. Direct thrombin inhibitors such as dabigatran and very short heparin molecules such as fondaparinux are less susceptible to influence than long-chain heparins, suggesting a possible therapeutic advantage.

\section{Authorship Contributions}

Participated in research design: Ammollo, F. Semeraro, Colucci.

Conducted experiments: Ammollo, F. Semeraro.

Performed data analysis: Ammollo, F. Semeraro, Colucci.

Wrote or contributed to the writing of the manuscript: Ammollo,

F. Semeraro, Carratù, N. Semeraro, Colucci.

\section{References}

Abrams ST, Zhang N, Manson J, Liu T, Dart C, Baluwa F, Wang SS, Brohi K, Kipar $\mathrm{A}$, and $\mathrm{Yu} \mathrm{W}$, et al. (2013) Circulating histones are mediators of trauma-associated lung injury. Am J Respir Crit Care Med 187:160-169.

Agnelli G (2004) Prevention of venous thromboembolism in surgical patients. Circulation 110(24, Suppl 1)IV4-IV12.

Alban S (2005) From heparins to factor Xa inhibitors and beyond. Eur J Clin Invest 35 (Suppl 1):12-20.

Ammollo CT, Semeraro F, Incampo F, Semeraro N, and Colucci M (2010) Dabigatran enhances clot susceptibility to fibrinolysis by mechanisms dependent on and independent of thrombin-activatable fibrinolysis inhibitor. J Thromb Haemost 8:790-798.

Ammollo CT, Semeraro F, Semeraro N, and Colucci M (2009) The contribution of anti-Xa and anti-IIa activities to the profibrinolytic activity of low-molecularweight heparins. Thromb Haemost 101:782-785.

Ammollo CT, Semeraro F, Xu J, Esmon NL, and Esmon CT (2011) Extracellular histones increase plasma thrombin generation by impairing thrombomodulindependent protein C activation. J Thromb Haemost 9:1795-1803.

Binetti BM, Rotunno C, Tripodi A, Asti D, Semeraro F, Semeraro N, and Colucci M (2006) Hyperprothrombinaemia-induced APC resistance: differential influence on fibrin formation and fibrinolysis. Thromb Haemost 95:606-611.

Borissoff JI, Joosen IA, Versteylen MO, Brill A, Fuchs TA, Savchenko AS, Gallant M, Martinod K, Ten Cate H, and Hofstra L, et al. (2013) Elevated levels of circulating DNA and chromatin are independently associated with severe coronary atherosclerosis and a prothrombotic state. Arterioscler Thromb Vasc Biol 33:2032-2040.

Brill A, Fuchs TA, Savchenko AS, Thomas GM, Martinod K, De Meyer SF, Bhandari $\mathrm{AA}$, and Wagner DD (2012) Neutrophil extracellular traps promote deep vein thrombosis in mice. J Thromb Haemost 10:136-144.

Brufatto N, Ward A, and Nesheim ME (2003) Factor Xa is highly protected from antithrombin-fondaparinux and antithrombin-enoxaparin when incorporated into the prothrombinase complex. J Thromb Haemost 1:1258-1263.

Chen R, Kang R, Fan XG, and Tang D (2014) Release and activity of histone in diseases. Cell Death Dis 5:e1370.

Chiu HM, Hirsh J, Yung WL, Regoeczi E, and Gent M (1977) Relationship between the anticoagulant and antithrombotic effects of heparin in experimental venous thrombosis. Blood 49:171-184

Crowther MA, Berry LR, Monagle PT, and Chan AK (2002) Mechanisms responsible for the failure of protamine to inactivate low-molecular-weight heparin. $\mathrm{Br} J$ Haematol 116:178-186.

Dahl OE, Harenberg J, Wexels F, and Preissner KT (2015) Arterial and venous thrombosis following trauma and major orthopedic surgery: molecular mechanisms and strategies for intervention. Semin Thromb Hemost 41:141-145.

Demers M and Wagner DD (2014) NETosis: a new factor in tumor progression and cancer-associated thrombosis. Semin Thromb Hemost 40:277-283.

Eriksson BI, Dahl OE, Huo MH, Kurth AA, Hantel S, Hermansson K, Schnee JM, and Friedman RJ; RE-NOVATE II Study Group (2011) Oral dabigatran versus enoxaparin for thromboprophylaxis after primary total hip arthroplasty (RE-NOVATE II*). A randomised, double-blind, non-inferiority trial. Thromb Haemost 105:721-729.

Freeman CG, Parish CR, Knox KJ, Blackmore JL, Lobov SA, King DW, Senden TJ, and Stephens RW (2013) The accumulation of circulating histones on heparan sulphate in the capillary glycocalyx of the lungs. Biomaterials 34:5670-5676.

Fuchs TA, Abed U, Goosmann C, Hurwitz R, Schulze I, Wahn V, Weinrauch Y, Brinkmann V, and Zychlinsky A (2007) Novel cell death program leads to neutrophil extracellular traps. J Cell Biol 176:231-241.

Fuchs TA, Bhandari AA, and Wagner DD (2011) Histones induce rapid and profound thrombocytopenia in mice. Blood 118:3708-3714.

Fuchs TA, Brill A, Duerschmied D, Schatzberg D, Monestier M, Myers DD, Jr, Wrobleski SK, Wakefield TW, Hartwig JH, and Wagner DD (2010) Extracellular DNA traps promote thrombosis. Proc Natl Acad Sci USA 107:15880-15885.

Fuchs TA, Kremer Hovinga JA, Schatzberg D, Wagner DD, and Lämmle B (2012) Circulating DNA and myeloperoxidase indicate disease activity in patients with thrombotic microangiopathies. Blood 120:1157-1164.

Fürnrohr BG, Groer GJ, Sehnert B, Herrmann M, and Voll RE (2007) Interaction of histones with phospholipids-implications for the exposure of histones on apoptotic cells. Autoimmunity 40:322-326.

Hemker HC, Al Dieri R, De Smedt E, and Béguin S (2006) Thrombin generation, a function test of the haemostatic-thrombotic system. Thromb Haemost 96:553-561. Hirsh J, Warkentin TE, Shaughnessy SG, Anand SS, Halperin JL, Raschke R, Granger C, Ohman EM, and Dalen JE (2001) Heparin and low-molecular-weight heparin: mechanisms of action, pharmacokinetics, dosing, monitoring, efficacy, and safety. Chest 119(1, Suppl)64S-94S.
Johnston RB, Jr, Keele BB, Jr, Misra HP, Lehmeyer JE, Webb LS, Baehner RL, and RaJagopalan KV (1975) The role of superoxide anion generation in phagocytic bactericidal activity. Studies with normal and chronic granulomatous disease leukocytes. J Clin Invest 55:1357-1372.

Kannemeier C, Shibamiya A, Nakazawa F, Trusheim H, Ruppert C, Markart P, Song Y, Tzima E, Kennerknecht E, and Niepmann M, et al. (2007) Extracellular RNA constitutes a natural procoagulant cofactor in blood coagulation. Proc Natl Acad Sci USA 104:6388-6393.

Lane DA, Pejler G, Flynn AM, Thompson EA, and Lindahl U (1986) Neutralization of heparin-related saccharides by histidine-rich glycoprotein and platelet factor 4 . J Biol Chem 261:3980-3986.

Levi M (2014) The dual face of heparin in severe infection. Blood 123:947-948.

Lisman T, Adelmeijer J, Nieuwenhuis HK, and de Groot PG (2003) Enhancement of fibrinolytic potential in vitro by anticoagulant drugs targeting activated factor X, but not by those inhibiting thrombin or tissue factor. Blood Coagul Fibrinolysis 14:557-562.

Longstaff C, Varjú I, Sótonyi P, Szabó L, Krumrey M, Hoell A, Bóta A, Varga Z, Komorowicz E, and Kolev K (2013) Mechanical stability and fibrinolytic resistance of clots containing fibrin, DNA, and histones. J Biol Chem 288:6946-6956.

Morita S, Gebska MA, Kakkar AK, and Scully MF (2001) High affinity binding of heparin by necrotic tumour cells neutralises anticoagulant activity-implications for cancer related thromboembolism and heparin therapy. Thromb Haemost 86:616-622. Pal PK, Starr T, and Gertler MM (1983) Neutralization of heparin by histone and its subfractions. Thromb Res 31:69-79.

Pemberton AD, Brown JK, and Inglis NF (2010) Proteomic identification of interactions between histones and plasma proteins: implications for cytoprotection. Proteomics 10:1484-1493.

Savchenko AS, Martinod K, Seidman MA, Wong SL, Borissoff JI, Piazza G, Libby P, Goldhaber SZ, Mitchell RN, and Wagner DD (2014) Neutrophil extracellular traps form predominantly during the organizing stage of human venous thromboembolism development. J Thromb Haemost 12:860-870.

Semeraro F, Ammollo CT, Esmon NL, and Esmon CT (2014) Histones induce phosphatidylserine exposure and a procoagulant phenotype in human red blood cells. J Thromb Haemost 12:1697-1702.

Semeraro F, Ammollo CT, Gils A, Declerck PJ, and Colucci M (2013) Monoclonal antibodies targeting the antifibrinolytic activity of activated thrombin-activatable fibrinolysis inhibitor but not the anti-inflammatory activity on osteopontin and C5a. J Thromb Haemost 11:2137-2147.

Semeraro F, Ammollo CT, Morrissey JH, Dale GL, Friese P, Esmon NL, and Esmon CT (2011) Extracellular histones promote thrombin generation through platelet-dependent mechanisms: involvement of platelet TLR2 and TLR4. Blood 118:1952-1961.

Semeraro F, Piro D, Rossiello MR, Ammollo T, and Colucci M (2007) Profibrinolytic activity of the direct thrombin inhibitor melagatran and unfractionated heparin in platelet-poor and platelet-rich clots. Thromb Haemost 98:1208-1214.

Silvain J, Beygui F, Barthélémy O, Pollack C, Jr, Cohen M, Zeymer U, Huber K, Goldstein P, Cayla G, and Collet JP, et al. (2012) Efficacy and safety of enoxaparin versus unfractionated heparin during percutaneous coronary intervention: systematic review and meta-analysis. BMJ 344:e553.

Siragusa S, Cosmi B, Piovella F, Hirsh J, and Ginsberg JS (1996) Low-molecular-weight heparins and unfractionated heparin in the treatment of patients with acute venous thromboembolism: results of a meta-analysis. Am J Med 100:269-277.

Urban CF, Ermert D, Schmid M, Abu-Abed U, Goosmann C, Nacken W, Brinkmann V, Jungblut PR, and Zychlinsky A (2009) Neutrophil extracellular traps contain calprotectin, a cytosolic protein complex involved in host defense against Candida albicans. PLoS Pathog 5:e1000639.

van Montfoort ML, Stephan F, Lauw MN, Hutten BA, Van Mierlo GJ, Solati S, Middeldorp S, Meijers JC, and Zeerleder S (2013) Circulating nucleosomes and neutrophil activation as risk factors for deep vein thrombosis. Arterioscler Thromb Vasc Biol 33:147-151.

Van Ryn-McKenna J, Ofosu FA, Gray E, Hirsh J, and Buchanan MR (1989) Effects of dermatan sulfate and heparin on inhibition of thrombus growth in vivo. Ann NY Acad Sci 556:304-312.

Varin R, Mirshahi S, Mirshahi P, Kierzek G, Sebaoun D, Mishal Z, Vannier JP, Yvonne Borg J, Simoneau G, and Soria C, et al. (2007) Clot structure modification by fondaparinux and consequence on fibrinolysis: a new mechanism of antithrombotic activity. Thromb Haemost 97:27-31.

Wildhagen KC, García de Frutos P, Reutelingsperger CP, Schrijver R, Aresté C, Ortega-Gómez A, Deckers NM, Hemker HC, Soehnlein O, and Nicolaes GA (2014) Nonanticoagulant heparin prevents histone-mediated cytotoxicity in vitro and improves survival in sepsis. Blood 123:1098-1101.

Xu J, Zhang X, Pelayo R, Monestier M, Ammollo CT, Semeraro F, Taylor FB, Esmon NL, Lupu F, and Esmon CT (2009) Extracellular histones are major mediators of death in sepsis. Nat Med 15:1318-1321.

Yamamichi S, Fujiwara Y, Kikuchi T, Nishitani M, Matsushita Y, and Hasumi K (2011) Extracellular histone induces plasma hyaluronan-binding protein (factor VII activating protease) activation in vivo. Biochem Biophys Res Commun 409:483-488.

Yusuf S, Mehta SR, Chrolavicius S, Afzal R, Pogue J, Granger CB, Budaj A, Peters RJ, Bassand JP, and Wallentin L, et al.; Fifth Organization to Assess Strategies in Acute Ischemic Syndromes Investigators (2006) Comparison of fondaparinux and enoxaparin in acute coronary syndromes. $N$ Engl J Med 354:1464-1476.

Address correspondence to: Fabrizio Semeraro, Department of Biomedical Sciences and Human Oncology, Section of General and Experimental Pathology, University of Bari "Aldo Moro," Piazza G. Cesare 11, 70124 Bari, Italy. E-mail: brizioraro@hotmail.com 